\title{
Inhibition of root penetration in subsurface driplines by impregnating the drippers with copper oxide particles
}

\author{
Seba Schifris ${ }^{1} \cdot$ Avi Schweitzer $^{1} \cdot$ Eli Matan $^{1} \cdot$ Gadi Borkow $^{2}$
}

Received: 28 May 2014 / Accepted: 30 March 2015 / Published online: 10 April 2015

(C) The Author(s) 2015. This article is published with open access at Springerlink.com

\begin{abstract}
Clogging of subsurface drip irrigation (SDI) systems by root penetration into the emitters results in inappropriate water supply, increased replacement rates of SDI systems and increased costs. We found that impregnation of SDI drippers with copper oxide particles inhibits root penetration very significantly. The inhibition of root penetration varied from 24 to $76 \%$ of the control (60-80\% intrusion) depending on the copper oxide concentration of the drippers. The root penetration inhibition was demonstrated at two water flow rates, of 1 and $3.5 \mathrm{l} / \mathrm{h}$, and with new and used drippers after 1750 irrigation hours. Inhibition of root penetration occurred also if sewage water was used. The inhibition of root penetration into drippers was demonstrated with lettuce and tomato plants and reached similar efficacy as compared to the widely used herbicide Stomp ${ }^{\circledR}$ root penetration inhibition treatment. The amount of copper that leached into the water was below detection limit (less than $0.006 \mathrm{ppm}$ ). No loss of copper oxide particles was detected in drippers through which 33501 of water was passed (an amount of water that typically passes in SDI systems during 3-4 years of use), as determined by scanning electronic microscope and X-ray photoelectron spectrum analysis.
\end{abstract}

\section{Introduction}

Subsurface drip irrigation (SDI) is a very efficient irrigation system aimed at ensuring uniform and adequate supply of

Communicated by E. Fereres.

Gadi Borkow

gadi@cupron.com

Netafim Ltd., Derech Hashalom 10, 67892 Tel Aviv, Israel

2 Cupron Inc., Hasadnaot 10, 46733 Herzelia, Israel water to each plant according to its needs. Water is delivered directly to the roots of plants. This method prevents or minimizes evaporation and runoff and is especially useful in places where water is a limited resource.

A significant problem associated with SDI is the clogging of the emitters via root penetration. Roots tend to proliferate in favorable environments where water and nutrients are readily available, and the presence of a constant water and nutrient supply, emanating from the irrigation line emitters, favors root intrusion of the emitters. The root intrusion causes partial or total blockage of the dripper outlet. Depending on the aggressiveness of the root system and the type of the emitters, a number of adjoining emitters can be blocked, and in extreme cases, even a whole lateral, which in turn prevents water supply to downstream emitters.

One way to prevent root penetration is by treating the water or the drippers themselves with an herbicide, for example, with trifluralin (Sheval et al. 2008; Spera et al. 2006). The addition of the herbicide may necessitate an injection pump that releases the herbicide at a prescribed dosage and rate, or alternatively emitters may contain the herbicide. This provides a continuous slow release process of the herbicide as water passes through it. However, herbicide use carries risks that include environmental, ecological and human health effects (Ahemad and Khan 2009; Bernard et al. 2005; Eason et al. 2004). Another possibility of reducing root penetration has been the use of copper. Copper is known to have potent antibacterial, fungicidal and algaecidal properties (Borkow and Gabbay 2005; Murray-Gulde et al. 2002). Copper compounds are widely used today as algaecides and herbicides (Bishop and Rodgers 2012; Borkow and Gabbay 2005), and several soluble copper compounds have been shown to inhibit root elongation (Arduini et al. 1995; Meier et al. 2012). However, 
Fig. 1 Scanning electron microscopy (SEM) and X-ray photoelectron spectrum of untreated HDPE (a, b) and of HDPE containing $5 \%(\mathrm{w} / \mathrm{w})$ copper oxide particles $(\mathbf{c}, \mathbf{d})$
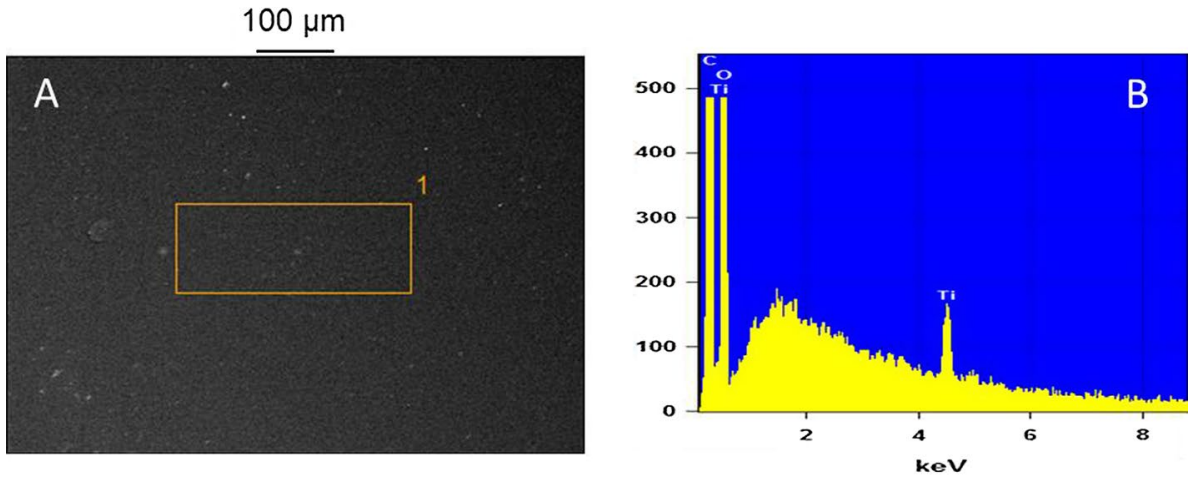

$100 \mu \mathrm{m}$
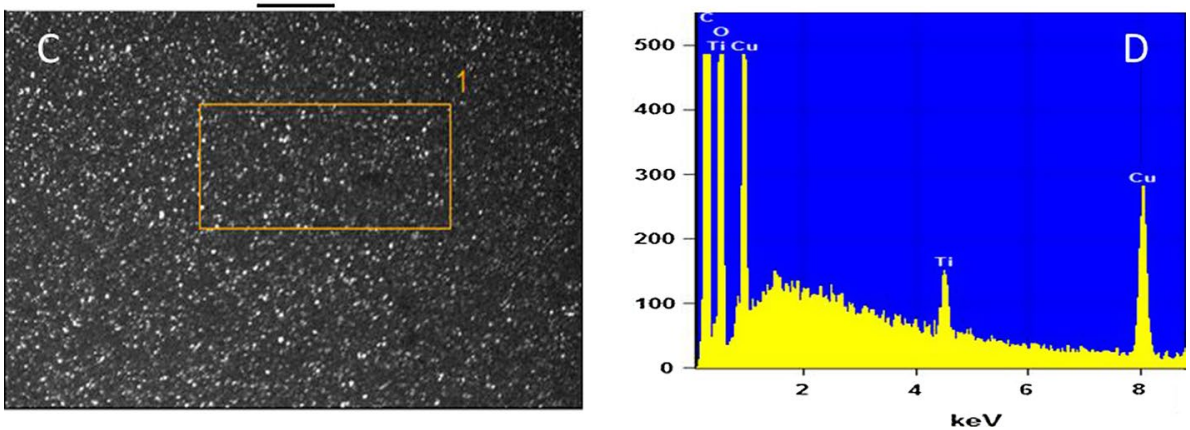

since these are chemicals that readily solubilize in water, they may have adverse environmental effects (de Andrade Waldemarin et al. 2012; Mastin and Rodgers 2000). Thus, non-soluble metallic copper pieces are being introduced in subsurface drip irrigation systems to protect the emitters from root intrusion (http://www.rainbird.com/landscape/ products/dripline/XFS.htm).

In the current study, we introduced non-soluble copper oxide particles in subsurface drip irrigation emitter heads and investigated their capacity to reduce root penetration and obstruction of the irrigation systems.

\section{Materials and methods}

\section{Introduction of copper oxide particles into emitter heads}

We introduced the copper oxide particles into polyethylene by using the published platform technology of introducing copper oxide particles into different polymeric materials (Borkow and Gabbay 2004). As can be seen in scanning electronic microscope pictures and the X-ray spectra analyses in Fig. 1, the copper oxide particles (the white dots seen in Fig. 1c) are homogenously distributed throughout the high-density polyethylene (HDPE) matrix and constitute an integral part of the dripper's head. The concentration of copper oxide particles introduced into the matrix varied between 0 and $40 \%$ weight/weight.

\section{Determination of root intrusion into drippers}

Experiments were generally performed as follows unless specified otherwise in the Results section: Individual, $4 \mathrm{~m}$ length, $0.5 \mathrm{~m}$ width and $0.35 \mathrm{~m}$ height, cases with an overall volume of 7001 were used as plots. Except in one case, the number of plots per experiment varied between 12 and 28 plots. The treatment of each plot was randomized. The cases were placed in a greenhouse in Kibbutz Hatzerim, Israel. The soil growth medium consisted of sand and compost at a 7/3 ratio. In each case, two subsurface irrigation lines (DripNet $\mathrm{PC}^{\mathrm{TM}}$ dripper lines or UniRam ${ }^{\mathrm{TM}} \mathrm{RC}$ or UniRam $^{\text {TM }}$ AS, Netafim) were installed $15 \mathrm{~cm}$ below the surface. Each line had 40 drippers. The distance between each dripper was $20 \mathrm{~cm}$, and each dripper flow rate, depending on the experiment, varied between 0.4 to $3.5 \mathrm{l} / \mathrm{h}$. At least four plots per treatment were used, i.e., 160 drippers. A total of 40 plant seedlings of $\sim 3$ weeks of age (lettuce or tomato, as detailed in the "Results" section) were planted in each case in two rows, being the distance between each row $20 \mathrm{~cm}$. Until plant establishment ( 7 days from seeding), the plants were watered daily by using Coolnet $\operatorname{Pro}^{\mathrm{TM}}$ mist emitters in addition to the watering regime that varied among experiments as described in Fig. 2. The watering regimes were designed to decrease gradually the amount of water applied in order to develop water stress and promote root intrusion into the drippers. During all experiments, the plants were treated via irrigation with a fertilizer composed of 6:4:4: nitrogen, phosphate and potassium, respectively, 
Fig. 2 Watering regimens of the different experiments performed to encourage root intrusion into the drippers
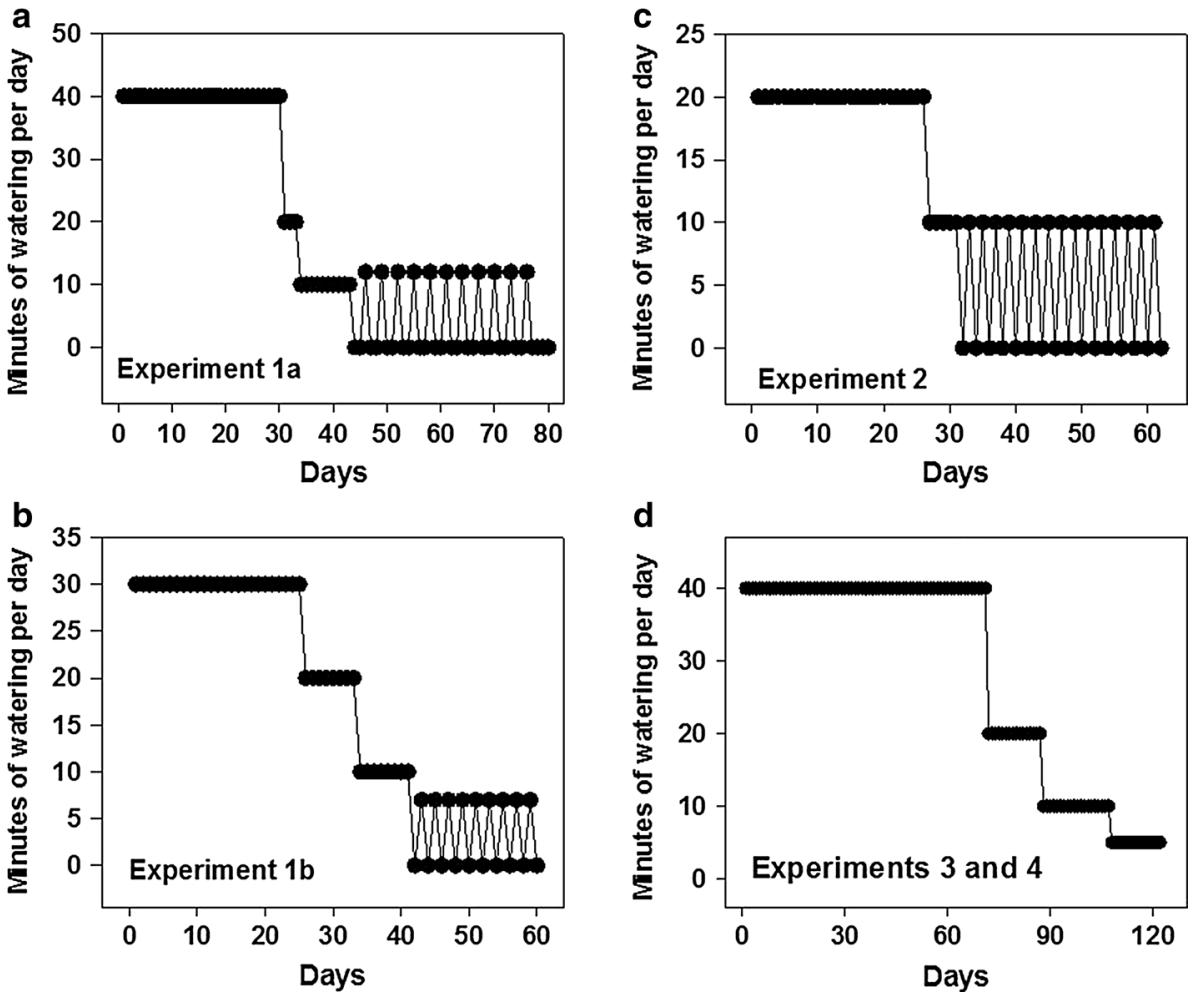

at $1.4 \mathrm{l} / \mathrm{m}^{3}$ daily application. At the end of the experiments, which varied between 2 and 4 months, the irrigation lines were removed, the drippers exposed and the root intrusion determined.

\section{Determination of copper elution from copper oxide-impregnated drippers}

The elution of copper from the copper oxide-impregnated drippers was determined in two different experimental settings. Firstly, the amount of copper eluting from a dripper containing copper oxide was determined by passing $250 \mathrm{ml}$ of tap water through the dripper at a flow rate of $1 \mathrm{l} / \mathrm{h}$. The water passing through the dripper was collected for $15 \mathrm{~min}$. The copper content of the collected $250 \mathrm{ml}$ water, and that present in $250 \mathrm{ml}$ of tap water that was not passed through the dripper, was determined by inductively coupled plasma mass spectrometry (ICP-MS, ARCOS, Spectro GMBH, Germany). Secondly, tap water was passed through a 15-m-long tube containing 50 copper oxideimpregnated drippers placed at a distance of $30 \mathrm{~cm}$ for a period of 140 days. A total of 33501 of water, at a flow rate of $1 \mathrm{l} / \mathrm{h}$, was circulated through the tubing. At the end of the experiment, the drippers were removed from the tubing and the presence of copper on the surface of eight drippers was examined by using scanning electronic microscopy (SEM; Jeol JMS 5410 LV scanning electron microscope, Japan) and the presence of copper coverage was determined by $\mathrm{X}$-ray photoelectron spectrum analysis (Link IV, ISIS,
Oxford Instruments, England). Eight copper oxide-containing drippers that were not exposed to water were used as reference.

\section{Results}

\section{Prevention of root intrusion}

\section{Experiment 1}

We first tested the effect on root intrusion into drippers impregnated with two different copper oxide concentrations, 12.5 and $25 \% \mathrm{w} / \mathrm{w}$, as compared to the control drippers without copper ( $n=4$ cases of 40 drippers each, per group). Three-week-old lettuce seedlings (Lactuca sativa, cultivar "yellow leaves") were grown for 80 days according to the water irrigation regimen depicted in Fig. 2a. As can be seen in Fig. 3a, there was a clear trend of reduction in root intrusion into the drippers with the increase in the copper oxide concentration in the dripper's heads; from $54 \%$ in the control to $43 \%$ (24\% reduction, $p=0.266$ ) and $31 \%$ (43\% reduction, $p=0.093$ ) in the drippers containing 12.5 and $25 \% \mathrm{w} / \mathrm{w}$ copper oxide particles, respectively.

We tested again the efficacy of reducing the root penetration by the $25 \%$ copper oxide-containing drippers as compared to the control drippers but enlarged the number of cases to 12 cases (480 drippers each) and used 3-weekold Lactuca sativa, Noga seedlings. Also in this experiment 

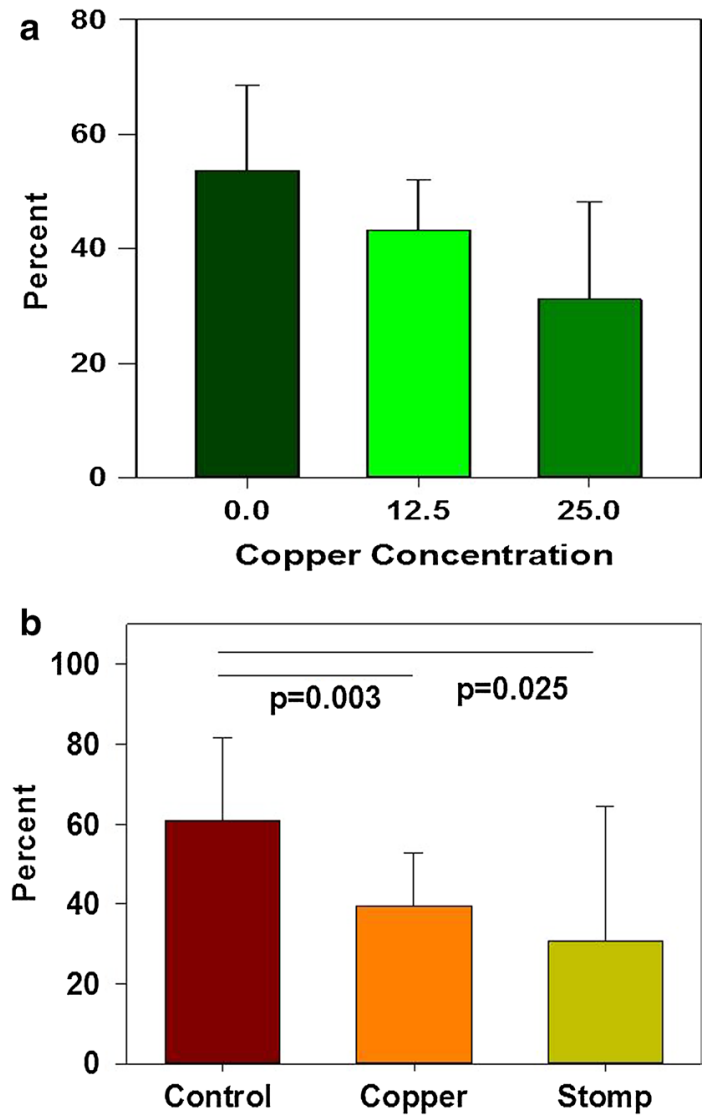

Fig. 3 a Mean and standard deviation of percent Lactuca sativa (cultivar "yellow leaves" seedlings) root intrusion into drippers with different copper oxide concentration $(n=160)$; b mean and standard deviation of percent Lactuca sativa (Noga seedlings) root intrusion for each type of dripper tested or Stomp ${ }^{\circledR}$ treatment $(n=480)$. The $p$ values of a $t$ test between the groups tested are shown

after 60 days of growth using the water regimen depicted in Fig. 2b, there was a reduction in root intrusion into the drippers containing the copper oxide particles as compared to the control ( $35 \%$ reduction, $p=0.003$, Fig. $3 b$ ). In addition, we tested the root penetration in four cases that contained 160 drippers without copper but that were treated with a widely used herbicide $\left(\right.$ Stomp $^{\circledR} 400$ SC, BASF, Ireland) via the irrigation system as instructed by the manufacturer. The drippers that were treated with Stomp ${ }^{\circledR}$ showed a similar overall reduction in root penetration as that seen in the copper oxide-containing drippers, but the variability was significantly higher (Fig. $3 b$ ).

\section{Experiment 2}

In this experiment, we examined whether there is a reduction in the efficacy of preventing root intrusion into the drippers containing $25 \%$ copper oxide particles after 10001 of water has passed through each dripper $(n=4$

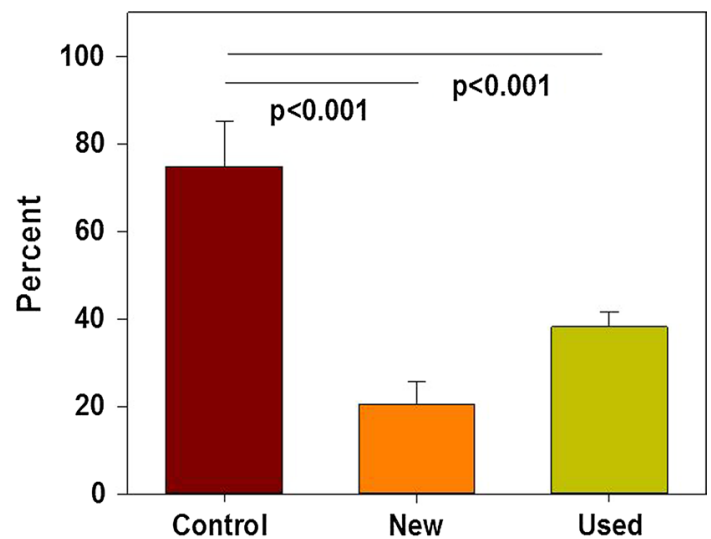

Fig. 4 Mean and standard deviation of percent Lactuca sativa ("yellow leaves" seedlings) root intrusion into new drippers or drippers through which 10001 of water was passed before performing the experiment $(n=160)$. The $p$ values of a $t$ test between the groups tested are shown

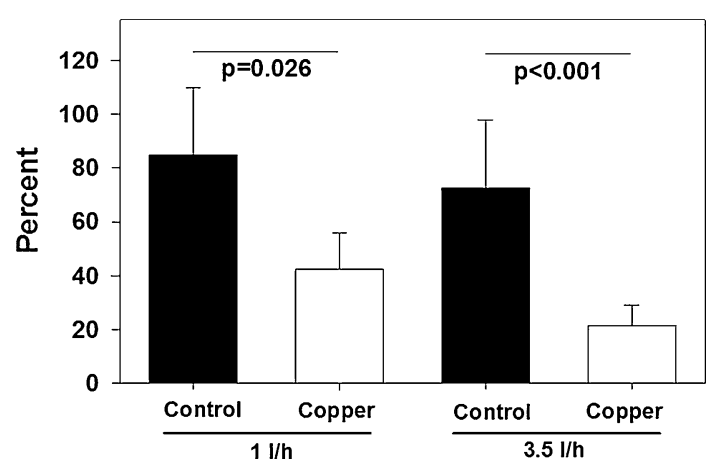

Fig. 5 Mean and standard deviation of percent tomato (Lycopersicon esculentum) root intrusion at 1 or $3.5 \mathrm{l} / \mathrm{h}$ water flow rate $(n=120)$. The $p$ values of a $t$ test between the groups tested are shown

cases of 40 drippers each, per group). We used Lactuca sativa, cultivar "yellow leaves" 3-week-old seedlings. As depicted in Fig. 4, the reduction in root penetration into the drippers containing copper oxide particles after 60 days of growth of growth using the water regimen depicted in Fig. 2c was even more drastic than in the first experiment using the same seedlings, from $\sim 75 \%$ in the control to $\sim 21 \%$ in the copper-containing drippers $(\sim 72 \%$ reduction, $p<0.001)$. Importantly, even in drippers through which 10001 of water was passed before performing the experiment, there were clear significant reductions ( $\sim 5 \%$ reduction, $p<0.001)$ in the root intrusion levels into the drippers as compared to the control.

\section{Experiment 3}

In this experiment, we examined the effect of the water flow rate on the capacity to reduce root intrusion by the copper 


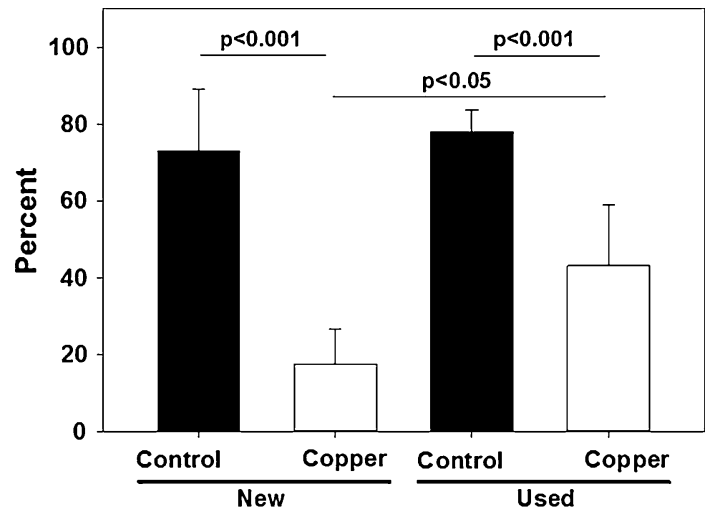

Fig. 6 Mean and standard deviation of percent tomato (Lycopersicon esculentum) root intrusion for new drippers or drippers in which 17201 of sewage water was first passed through them $(n=120)$. The $p$ values of a $t$ test between the groups tested are shown

oxide impregnation. We used two types of UniRam ${ }^{\mathrm{TM}}$ AS drippers, with flow rates of 1 and $3.5 \mathrm{l} / \mathrm{h}$. In each plot, 20 drippers were placed at a distance of $40 \mathrm{~cm}$ between each dripper. For each treatment, six plots were used with a total of 120 drippers per treatment. In each plot, two rows of 3-week-old tomato (Lycopersicon esculentum) seedlings were seeded with $40 \mathrm{~cm}$ distance between each seed in each row. The irrigation regime is described in Fig. 2c. As can be seen in Fig. 5, at a flow rate of $11 / \mathrm{h}$, the presence of copper oxide particles in the drippers reduced the root intrusion into the drippers after 120 days by $50 \%(p=0.026)$, while at a flow rate of $3.51 / \mathrm{h}$, the root intrusion reduction as compared to the control was reduced by $70 \%(p<0.001)$.

\section{Experiment 4}

In this last experiment, we examined whether the capacity of the drippers to inhibit root intrusion is affected when sewage water is used. We used UniRam ${ }^{\mathrm{TM}}$, either new or used drippers through which 17201 of sewage water was first passed at a flow rates of $1 \mathrm{l} / \mathrm{h}$, which customarily corresponds to 1.5-2 years of operation in the field. In each plot, 20 drippers were placed at a distance of $40 \mathrm{~cm}$ between each dripper. For each treatment, five plots were used with a total of 100 drippers per treatment. In each plot, two rows of 3-week-old tomato (Lycopersicon esculentum) seedlings were seeded with $40 \mathrm{~cm}$ distance between each seed in each row. The irrigation regime is detailed in Fig. 2d. As can be seen in Fig. 6, the presence of copper oxide particles in the new drippers reduced the root intrusion into the drippers by $76 \%$, from a mean of 73 to $17.5 \%$ intrusion $(p<0.001)$, after 120 days of growth. Also the used drippers significantly reduced the root intrusion into the dripper, from a mean 78 to $43 \%(p<0.001)$, although as compared to the new drippers, there was reduced efficacy $(p=0.013)$.

\section{Copper elution from drippers}

The amount of copper in $250 \mathrm{ml}$ of water before and after passing through a dripper containing copper oxide was less than $0.006 \mathrm{ppm}(\mathrm{mg} / \mathrm{l})$, which is the lower limit of detection of the assay. Copper oxide particles were present on the surface of the HDPE drippers containing $25 \%$ copper oxide $\mathrm{w} / \mathrm{w}$, with no observable differences in the coverage in those not exposed or those exposed to 33501 of water. The percentage of copper coverage on the surface of eight separate drippers though which 33501 of water passed at a flow rate of $1 \mathrm{l} / \mathrm{h}$ during 140 days was $2 \%$ lower in average than those found in eight separate drippers not exposed to water, as determined by SEM and X-ray photoelectron spectrum analysis $(11.71 \pm 0.53$ vs $11.48 \pm 1.59) .33501$ of water that passed through the drippers is equivalent to 3-4 years of irrigation using such flow rate irrigation system in a field.

\section{Discussion and conclusions}

A typical life span of SDI could be 15-20 years and depends of several factors, such as the type of water used, the bioflora that develops within the irrigation system, the maintenance treatment and the level of root intrusion into the emitters (Lamm et al. 2011). In this study, we analyzed the capacity of reducing root intrusion into the emitters by incorporating microscopic copper particles during the manufacture of the emitters, as copper is known as a potent algaecide (Borkow and Gabbay 2005; Murray-Gulde et al. 2002).

We used copper oxide for two main reasons: (a) copper oxide is a very reactive copper compound with potent biocidal properties, which is being used successfully in many consumer, industrial and medical device products (Borkow and Gabbay 2004, 2006; Borkow et al. 2007, 2010a, b; Borkow and Monk 2012; Borkow 2012), and (b) copper oxide is a non-soluble copper compound. Obviously in such products, it is important that the active ingredient in the product remains in the product for the life of the product; in this case that it would not be lost into the running water.

As was demonstrated in this study, impregnating the copper oxide particles into the drippers indeed very significantly reduced the root intrusion into the drippers, as demonstrated in all five experiments conducted. As expected, the reduction in the root intrusion was copper dose dependent. The inhibition of root intrusion occurred both in tomato and lettuce plants with different root system, supporting the notion that the effect is universal and not plant specific, although additional trials should test this hypothesis. The efficacy reached is similar to the current standard, 
i.e., treatment with Stomp ${ }^{\circledR}$. Replacing Stomp ${ }^{\circledR}$ is advantageous as Stomp ${ }^{\circledR}$ treatment is environmentally unfriendly and time consuming, and in some countries its use is forbidden. Irrigation water can vary very much. Importantly, even when using sewage water, rich in organic material that can interact with the copper and quench the algaecidal efficacy, a very significant reduction in root intrusion was observed. The inhibition of root intrusion occurred both in dripper flow rate of 1 and $3.5 \mathrm{l} / \mathrm{h}$. Both of these flow rates are very common in drip irrigation systems.

In conclusion, in this study we demonstrated that incorporation of copper oxide particles into the dripper's heads of SDI lines significantly and consistently reduced root penetration into the drippers. The efficacy is maintained even after very prolonged use allowing for reducing the frequency needed for replacing SDI systems.

Acknowledgments This study was funded by Netafim Ltd.

Open Access This article is distributed under the terms of the Creative Commons Attribution 4.0 International License (http://creativecommons.org/licenses/by/4.0/), which permits unrestricted use, distribution, and reproduction in any medium, provided you give appropriate credit to the original author(s) and the source, provide a link to the Creative Commons license, and indicate if changes were made.

\section{References}

Ahemad M, Khan MS (2009) Toxicity assessment of herbicides quizalofop-p-ethyl and clodinafop towards Rhizobium pea symbiosis. Bull Environ Contam Toxicol 82:761-766

Arduini I, Godbold DL, Onnis A (1995) Influence of copper on root growth and morphology of Pinus pinea L. and Pinus pinaster Ait. seedlings. Tree Physiol 15:411-415

Bernard H, Chabalier PF, Chopart JL, Legube B, Vauclin M (2005) Assessment of herbicide leaching risk in two tropical soils of Reunion Island (France). J Environ Qual 34:534-543

Bishop WM, Rodgers JH Jr (2012) Responses of Lyngbya wollei to exposures of copper-based algaecides: the critical burden concept. Arch Environ Contam Toxicol 62:403-410

Borkow G (2012) Using copper to fight microorganisms. Curr Chem Biol 6:93-103

Borkow G, Gabbay J (2004) Putting copper into action: copperimpregnated products with potent biocidal activities. FASEB J 18:1728-1730
Borkow G, Gabbay J (2005) Copper as a biocidal tool. Curr Med Chem 12:2163-2175

Borkow G, Gabbay J (2006) Endowing textiles with permanent potent biocidal properties by impregnating them with copper oxide. JTATM 5:1-3

Borkow G, Monk AB (2012) Fighting nosocomial infections with biocidal non-intrusive hard and soft surfaces. World J Clin Infect Dis 12:77-90

Borkow G, Sidwell RW, Smee DF, Barnard DL, Morrey JD, Lara-Villegas HH, Shemer-Avni Y, Gabbay J (2007) Neutralizing viruses in suspensions by copper oxide based filters. Antimicrob Agents Chemother 51:2605-2607

Borkow G, Okon-Levy N, Gabbay J (2010a) Copper oxide impregnated wound dressings: biocidal and safety studies. Wounds 22:310-316

Borkow G, Zhou SS, Page T, Gabbay J (2010b) A novel anti-influenza copper oxide containing respiratory face mask. PLoS One 5:e11295

de Andrade Waldemarin KC, Alves RN, Beletti ME, Rantin FT, Kalinin AL (2012) Copper sulfate affects Nile tilapia (Oreochromis niloticus) cardiomyocytes structure and contractile function. Ecotoxicology 21:783-794

Eason A, Tim US, Wang X (2004) Integrated modeling environment for statewide assessment of groundwater vulnerability from pesticide use in agriculture. Pest Manag Sci 60:739-745

Lamm FR, Rogers DH, Alam M, O'Brien DM, Trooien TP (2011) Twenty-two years of SDI research in Kansas. In: Proceedings of the 23rd Annual Central Plains Irrigation Conference, Burlington, CO., February 22-23, 2011. pp 68-92

Mastin BJ, Rodgers JH Jr (2000) Toxicity and bioavailability of copper herbicides (Clearigate, Cutrine-Plus, and copper sulfate) to freshwater animals. Arch Environ Contam Toxicol 39:445-451

Meier S, Alvear M, Borie F, Aguilera P, Ginocchio R, Cornejo P (2012) Influence of copper on root exudate patterns in some metallophytes and agricultural plants. Ecotoxicol Environ Saf 75:8-15

Murray-Gulde CL, Heatley JE, Schwartzman AL, Rodgers JH Jr (2002) Algicidal effectiveness of Clearigate, Cutrine-Plus, and copper sulfate and margins of safety associated with their use. Arch Environ Contam Toxicol 43:19-27

Sheval EV, Kazhura YI, Poleshuk NA, Lazareva EM, Smirnova EA, Maximova NP, Polyakov VY (2008) Trifluralin-induced disorganization of microtubular cytoskeleton alters the development of roots in Hordeum vulgare L. Acta Biol Hung 59:465-478

Spera G, Rosati S, Rossi E, Scicchitano S (2006) Subsurface drip irrigation with micro-encapsulated trifluralin. Trifluralin residues in soils and cultivations. Commun Agric Appl Biol Sci 71:161-170 